\title{
Исиченко А.П. \\ Система социально-педагогической подготовки осужденных к освобождению в исправительной колонии
}

Федеральное казенное учреждение «Научно-исследовательский институт Федеральной службы исполнения наказаний»

(Россия, Москва)

doi: 10.18411/trnio-09-2021-47

\section{Аннотация}

В статье рассматриваются вопросы реадизации системы социально-педагогической подготовки осужденных к освобождению в исправительной колонии, что оказывает всестороннее воздействие на личность осужденных, поскольку без проработки негативных особенностей их психологического состояния не представляется возможным проведение действительно эффективной педагогической работы по формированию у них необходимых для ресоциализации поведенческих характеристик.

Ключевые слова: социально-педагогической подготовки осужденных, ресоциализация, исправительное учреждение.

\section{Abstract}

The article deals with the issues of readization of the system of socio-pedagogical preparation of convicts for release in a correctional colony, which has a comprehensive impact on the personality of convicts, since without studying the negative features of their psychological state, it is not possible to conduct really effective pedagogical work on the formation of behavioral characteristics necessary for their resocialization.

Keywords: socio-pedagogical training of convicts, re-socialization, correctional institution.

В рамках реализации системы социально-педагогической подготовки осужденных к освобождению в исправительной колонии в формирующем эксперименте принимали участие 40 осужденных (ЭГ1) и 10 педагогов (ЭГ2). На формирующем этапе экспериментального исследования была разработана и реализована система социально-педагогической подготовки осужденных к освобождению в исправительной колонии. Данная система являлась основой функционирования на территории исправительного учреждения социально-психологического центра реабилитации и подготовки осужденных к освобождению (далее - Центр). Цели реализации указанной системы заключались в следующем: обеспечение ресоциализации осужденных, освоение ими основных социальных функций, как необходимых условий исправления и успешной адаптации в обществе после освобождения, как фундамента решения проблемы рецидивных проявлений среди лиц, освободившихся из исправительных учреждений; предоставление лицам, имеющим длительные сроки лишения свободы, возможности прохождения цикла социальнопсихологических тренингов и ролевых игр, включающих широкое информирование об изменениях в современном обществе.

В задачи реализации указанной системы работы входило: организация (оптимизация) целостного исправительного процесса осужденных при взаимодействии закрепленных за Центром сотрудников воспитательной службы, психологической лаборатории и социальных работников с сотрудниками других служб исправительного учреждения, педагогами общеобразовательной школы, преподавателями и мастерами профессионального училища, представителями общественности (привлечение общественных организаций к работе по повышению правосознания и правовой грамотности осужденных); разработка и развитие психотерапевтического направления работы психологов Центра социально-психологической реабилитации при оказании профильной психологической помощи осужденным заканчивающим отбывание длительных сроков лишения свободы; осуществление психологической поддержки осужденных, принявших решение об изменении делинквентной 
стратегии поведения на законопослушный образ жизнедеятельности; восстановление элементарных жизненных навыков у осужденных (забота об одежде, питании и жилье, умения правильно использовать зарплату и т.д.), выработка психоэмоциональной устойчивости при возникновении непрогнозируемых трудностей (например, при трудоустройстве, профессиональной ориентации, в межличностных отношениях - семья, родственники, друзья, соседи и т.д.), повышение личностной и социальной активности, обучение навыкам общения через расширение диапазона коммуникативных программ; подготовка эмпирического материала для рассмотрения возможности создания профилированных социально-психологических Центров реабилитации осужденных, не только направленных на подготовку осужденных к освобождению, но и по другим основаниям, тем самым обеспечение дифференцированного подхода в отношении различных категорий осужденных.

Концепция Центра строится на трех базовых аспектах: «труд, трудовая занятость осужденных», «жизнь в группе», «коррекционные мероприятия». На предприятиях учреждения была организована трудовая занятость осужденных и их посменная работа (2 смены). Социально-психологический центр реабилитации и подготовки осужденных к освобождению позиционируется как жилой комплекс, представляющий собой «поле тренировки», в пределах которого моделируются различные ситуации повседневной жизнедеятельности, которые впоследствии прорабатываются (разбираются) в группе и должны в конечном итоге привести к «новым моделям поведения». Приравнивание жизненных условий, в т.ч. бытовых, создает предпосылку для принятия нового стиля поведения (адекватного жизни на свободе) и поддерживает просоциальное поведение.

Групповые коррекционные мероприятия в рамках реализации описываемой системы работы организовывались посредством целенаправленного воздействия на осужденных на занятиях. Основными формами воздействия на осужденных являлись: социальнопсихологический тренинг, как средство расширения уровня знаний, умений, повышения компетентности; ролевые игры; лекционные занятия, групповые дискуссии; совместная (осужденных и сотрудников) организация (планирование) досуга и празднико в/уборки/приготовления пищи; индивидуальная коррекционная и консультативная работа.

Исходя из теоретических аспектов ресоциализации и проблем реабилитации осужденных, в систему были включены семь равнозначных модулей, интериоризация которых способствовала повышению необходимых для успешного включения в жизнь после освобождения возможностей личности у осужденных. Специфическими модулями выступают:

1. Модуль социальной компетенции. Цель модуля: развитие способности осужденных эффективно взаимодействовать в системе межличностных отношений, освоение ими новых форм общения. Задачи, решаемые модулем: развитие коммуникативных навыков, расширение диапазона коммуникативных программ; умение ориентироваться в различных социальных ситуациях, определять особенности личности и эмоциональные состояния других людей; повышение способности построения адекватных социальных отношений; развитие понимания и учета интересов других в поведении (умение поставить себя на место другого, а также ознакомление с азами рефлексии и эмпатии); развитие политической, социальноэкономической и поликультурной ;развитие информационноинструментальной и информационно-личностной (этика поведения) компетенции.

В рамках реализации данного модуля использовались такие формы воздействия на осужденных как: социально-психологический тренинг (далее - СПТ), ролевая игра, групповая дискуссия.

2. Здоровьесберегающий модуль. Цели модуля: профилактика аддиктивного поведения (формирование позитивных аддикций); формирование образа 
жизни, способствующего укреплению здоровья. Задачи, решаемые модулем: повышение уровня информированности осужденных о формировании зависимости и последствиях негативных аддикций; обучение известным методикам оздоровления, очистки организма с помощью фитотерапии и физических упражнений; усвоение навыков ассертивного поведения (развитие уверенности в себе), как основы формирования мотивации на отказ от алкоголя/табакокурения/наркомании/игромании; изменение иерархии ценностных ориентаций осужденных с аддикциями (перефокусировка, перевод с негативных способов «получения удовольствий» на позитивные способы); повышение уровня эмпатии, проработка чувств, которые возникают при общении с человеком в алкогольном или наркотическом опьянении; психологическая поддержка осужденных, мотивированных на здоровый образ жизни; спортивный образ жизни, здоровое питание; информационное обеспечение профилактики заболеваний (личная гигиена, физическая культура и др); формирование адекватного поведения (борьба с вредными привычками).

В рамках реализации данного модуля использовались такие формы воздействия на осужденных как: СПТ, телесно-ориентированная и фито-терапия, аутогетеросуггестивное воздействие в комнате психоэмоциональной разгрузки, дискуссионные занятия с синемалогическими сеансами.

3. Модуль бытовой реадаптации. Цель модуля: выработка элементарных бытовых навыков, самообслуживания. Задачи, решаемые модулем: обучение основам кулинарии: технология приготовления пищи, благоприятные продукты для приготовления здоровой пищи; здоровое питание (рациональное питание); обучение навыкам использования бытовой техники (микроволновая печь, электрическая духовка, стиральная машина);обучение навыкам обращения с деньгами; обучение навыкам самообслуживания: стирка, уборка, глажение белья.

В рамках реализации данного модуля использовались такие формы воздействия на осужденных как: практические занятия на кухне и в коммунально-бытовой комнате, ролевая игра.

4. Модуль управления поведением. Цель модуля: развитие психоэмоциональной устойчивости и самообладания в критических ситуациях, психогигиена осужденных. Задачи, решаемые модулем: обучение приемам управления негативными эмоциями (гневом и агрессией); тренировка волевого самоконтроля в отношении проблемных реакций в поведении и ситуациях агрессии; развитие стрессоустойчивости; развитие чувства ответственности за свои поведенческие реакции; развитие чувства ответственности в социуме; развитие навыков самопознания, формирование адекватной самооценки; сохранение, поддержание и укрепление психического здоровья; обучение навыкам рационального поведения в конфликте.

В рамках реализации данного модуля использовались такие формы воздействия на осужденных как: СПТ, ролевая игра, работа в кабинете психоэмоциональной разгрузки.

5. Модуль жизненных перспектив. Цель модуля: повышение адаптивных возможностей личности по отношению к новым социальным ролям. Задачи, решаемые модулем: проработка причин преступления; обучение адекватному поведению в свободное время; выявление зон ближайшего и дальнего развития личности (проработка ресурсов личности), осознание индивидуальных качеств, способствующих личностному развитию; формирование адекватной жизненной перспективы; разработка личного жизненного плана осужденного; развитие социальных ресурсов личности; 
определение возможностей самовоспитания; оказание социальнопсихологической помощи семье осужденных.

В рамках реализации данного модуля использовались такие формы воздействия на осужденных как: СПТ, ролевая игра, организация дней «Открытых дверей».

6. Модуль социально-средовой реабилитации. Цели модуля: повышение уровня социальной адаптации субъекта к новым условиям жизнедеятельности, уровня его образовательной и профессиональной компетентности; профориентация осужденных. Задачи, решаемые модулем: информирование осужденных о возможностях получения различных форм образования, в том числе дистанционных; помощь осужденным в выборе сферы деятельности (профориентация в условиях несвободы), трудоустройстве, профессиональном обучении с учетом их индивидуальнотипических особенностей; изучение профессиональных установок личности осужденных; выработка (проигрывание) стилей поведения при трудоустройстве на работу, работа с рынком вакансий; консультации по правовым вопросам; обучение навыкам оформления документации на социальные услуги; развитие навыка обращения с деньгами; обучение основам кадрового консалтинга.

В рамках реализации данного модуля использовались такие формы воздействия на осужденных как: СПТ, ролевая игра, лекционные занятия.

7. Модуль семейных отношений. Цель модуля: формирование у осужденных правильного представления о семейных ценностях и традициях и осознания их как важных аспектов жизни каждого человека; формирование представления о психологических особенностях семьи. Задачи, решаемые модулем: информирование осужденных о том, какие функции выполняет семья; обучение осужденных практическим навыкам выхода из семейных конфликтных ситуаций; развитие навыка графически изображать родословную своей семьи; определение зависимости между моделями поведения в отцовской семье и того, как эти модели отражаются на отношениях супругов.

В рамках реализации данного модуля использовались такие формы воздействия на осужденных как: СПТ, групповая дискуссия, лекционные занятия.

Коррекционное воздействие на осужденных в рамках описываемой системы проводилось в течение полутора лет. С учетом работы осужденных в две смены (один из базовых аспектов ресоциализации их личности) и основных положений режимной службы на групповую социально-психологическую работу было отведено 1288 часов (по 215 часов на каждый независимый модуль).

С целью повышения эффективности групповых коррекционных занятий и лучшего усвоения осужденными предлагаемого материала почасовая тематика занятий строилась с учетом численности групп заключенных, в которые входило до 10 человек (четыре группы осужденных I и II смены). Согласно нормативной нагрузке, количеству времени, необходимому на подготовку групповых психокоррекционных мероприятий, и наибольшему охвату количества осужденных, которые описаны в Приказе Минюста России «Об утверждении инструкции по организации деятельности психологической службы уголовноисполнительной системы», осуществлялась одновременная работа по двум независимым модулям [1].

Для проведения работы были оборудованы 3 кабинета. Один из них являлся рабочим, где был расположен рабочий стол на двух человек, два компьютера и шкаф для хранения документации. Здесь же с помощью нитевой шторы была выделена зона индивидуальной работы. Второй кабинет - это комната для групповой работы. Кабинеты для индивидуальной и групповой работы были обеспечены всеми необходимыми дидактическими материалами. В них также имелась доска и пишущие материалы для работы. Кабинеты были оборудованы 
столами и стульями, расположение и состояние которых соответствовали санитарноэпидемиологическим требованиям к условиям организации обучения в общеобразовательных организациях [2].

Третий кабинет - это сенсорная комната, которая оборудовалась согласно Приказу Минздрава РФ «О психотерапевтической помощи» и содержала расширенное количество специализированных приборов для оказания положительного психологического воздействия на осужденных [3]. Площадь сенсорной помощи составляла 16 кв.м, поэтому, согласно санитарно-гигиеническим требованиям, одновременно в кабинете могло заниматься до 8 человек. В комнате не ощущались шум, вибрация и другие неблагоприятные факторы окружающей среды. Она была обеспечена приточно-вытяжной вентиляцией. Цветосветовое решение интерьера - белый цвет стен (окрашенные) и насыщенные яркие акценты в мебели и оборудовании. Пол был покрыт линолеумом на мягкой основе.

Для создания данной комнаты были приобретены различные виды оборудования: кресла-груши (бескаркасные кресла), зеркальный шар с мотором, профессиональный источник света к зеркальному шару «Зебра-50», безопасный оптиковолоконный пучок «Звездный дождь» (волокна можно перебирать, держать, обматывать вокруг рук, тела, лежать на них, переливающиеся цвета привлекают внимание и успокаивают, развивают тонкую моторику), аромолампа и ионизатор воздуха, сенсорная панель, безопасная пузырьковая колонна с мягкой платформой и безопасным угловым зеркалом из 2-х частей, аудиосистема в комплекте с беспроводными наушниками, видеосистема (телевизор, домашний кинотеатр).

Сеансы в сенсорной комнате были направлены на решение следующих задач: снятие мышечного и психоэмоционального напряжения, достижение состояния релаксации и душевного равновесия; создание положительного эмоционального фона и помощь в преодолении нарушения в эмоционально-волевой сфере; развитие общей и мелкой моторики; активация различных функций центральной нервной системы за счет создания обогащенной мультисенсорной среды; стимуляция ослабленных сенсорных функций (зрение, осязание, слух и т.д.); реабилитация осужденных с повышенной агрессивностью.

В сенсорной комнате также проводились тренинговые занятия.

Время сеансов в сенсорной комнате составляло около 40-45 минут. Занятия проводились подгруппами по 4-8 человек или индивидуально. Методики работы были ориентированы на расширение психотерапевтического направления. В сенсорной комнате были созданы условия для работы с применением светотерапии, цветотерапии, звукотерапии, музыкотерапии, ароматерапии.

Кроме того, работа с осужденными включала в себя организацию встреч с представителями общественных и религиозных организаций. Религиозное просвещение заключенных осуществлялось путем проведения бесед в православном храме. Стоит отметить, что данное помещение частично оборудовалось самими осужденными, что явилось основой для привития им уважения к религии. Ежемесячно исправительное учреждение посещал священнослужитель, который проводил с осужденными религиозные беседы, обряды, лекции религиозного характера, приобщал их к моральным и духовным ценностям, а также, по мере возможностей, оказывал гуманитарную помощь в виде религиозной литературы и периодических изданий. Священнослужителем проводилась просветительская работа среди верующих осужденных, направленная на устранение противоправных установок личности, вызванных незнанием догм нравоучения.

Посещение храма и занятий со священнослужителем проходило на добровольной основе во избежание развития враждебности по отношению к религии и ее представителям. Передаваемая в исправительное учреждение религиозная литература проверялась на предмет наличия в ней содержания экстремистского толка. Педагогами, вне религиозных занятий, проводилась разъяснительная работа среди осужденных об уголовной ответственности за участие в экстремистской деятельности и распространение экстремистских материалов. 
С целью взаимодействия осужденных с представителями правоохранительных органов и общественных организаций в рамках рассматриваемой системы осуществлялись мероприятия, подготовленные совместно психологами, социальными работниками и начальником отряда. Как правило, они посвящались каким-либо важным или актуальным для Центра датам. За время реализации системы были проведены следующие мероприятия: 1 Мая - праздник Весны и Труда; 9 Мая - День победы; 31 мая - Всемирный день отказа от курения; 1 июня - Международный день защиты детей; 12 июня - День России; 27 августа День открытых дверей учреждении; 1 октября - День добра и уважения пожилых людей; 4 ноября - День народного единства; Встречаем Новый год.

Во время этих мероприятий использовались такие виды работ, как групповые дискуссии, просмотр документальных и художественных фильмов, лекции, оформление стенгазет. Накоплен стимульный материал, составляется фотоотчет.

Кроме того, были введены в практику поздравления осужденных с Днем Рождения. В этот день для осужденного готовится открытка с поздравлениями и преподносится на занятии. Несколько раз в ответ на это осужденные организовывали своими силами чаепитие, которое проходило по окончанию занятия со всеми сотрудниками и осужденными, присутствующими в Центре.

В холле было оформлено три информационных стенда. Первый для расписания. Второй содержал в себе необходимую информацию, которая может пригодиться любому осужденному. Этот стенд оформляют и начальник отряда, и психологи, и педагоги, и социальные работники. И третий стенд, название которого «Жизнь отряда», говорит сам за себя: сюда помещаются фотографии, сделанные во время различных мероприятий, либо стенгазеты, оформленные самими осужденными, посвященные различным праздничным датам. Многие осужденные в Центре приобщаются к чтению. Для этого силами сотрудников и осужденных Центра была создана библиотека с художественной и специальной литературой.

Для реализации целей постпенитенциарного сопровождения осужденных было организовано взаимодействие Центра с Центрами занятости населения, участковыми пунктами полиции, действующими на территориях проживания бывших осужденных, а также с различными социальными службами. В ходе постпенитенциарного сопровождения осуществлялся контроль за исполнением участниками эксперимента правовых обязанностей, вытекающих из освобождения (получение документов, постановка на учет в органах МВД по месту жительства). Кроме того, силами Центром занятости и социальных служб организовывалась помощь осужденным в поиске работы и получении им положенной социально помощи.

Как видно, в рамках описываемой системы социально-педагогической подготовки осужденных к освобождению в исправительной колонии осуществлялась работа как по педагогическому, так и по психологическому направлениями. Это позволяло оказывать всестороннее воздействие на личность осужденных, поскольку без проработки негативных особенностей их психологического состояния не представлялось возможным проведение действительно эффективной педагогической работы по формированию у них необходимых для ресоциализации поведенческих характеристик.

Кроме того, в рамках указанной системы работы осуществлялась деятельность по развитию профессиональных навыков педагогов, работающих в исправительных учреждениях и занятых в социально-педагогической подготовке осужденных к освобождению. В рамках данной деятельности была реализована программа профессионального совершенствования педагогов. Цель данной программы состояла в развитии профессиональных компетенций педагогов исправительных учреждений, занятых в социально-педагогической подготовке осужденных к освобождению. Концепцию программы составляла направленность на непрерывное развитие и постоянный поиск решений профессиональной педагогической деятельности. В задачи программы входило следующее: овладение учебно-методическими и информационно-методическими ресурсами, 
необходимыми для успешного решения задач, возникающих в процессе социальнопедагогической подготовки осужденных к освобождению; повышение профессиональной компетентности путем использования современных педагогических, информационнокомпьютерных и здоровьесберегающих технологий; создание условий для развития индивидуальных способностей и оказания творческой и интеллектуальной поддержки педагогам.

В соответствии с указанными задачами, программа работы с педагогами включала следующие направления.

1. Изучение литературы, связанной с проблемами профессионального развития в сфере педагогической работы с осужденными. В рамках указанного направления педагоги изучали юридическую документацию, связанную с особенностями организации образовательной деятельности в учреждениях уголовно-исполнительной системы РФ, а также научные работы, статьи и исследования по проблемам особенностей и закономерностей педагогического процесса в исправительных учреждениях уголовноисполнительной системы РФ, повторяли и обсуждали понятие «социальнопедагогическая подготовка» и его определение, рассматривали различные модели организации данного процесса в РФ и зарубежом, определяли наиболее проблемные места его реализации. Кроме того, проводилось рассмотрение и обсуждение действующей на их непосредственном месте работы образовательной программы для осужденных, а также реализуемых мер по их подготовке к освобождению. Изучение научно-методической литературы также включало выделение и обсуждение методических рекомендаций для педагогических работников исправительных учреждений, занятых в процессе ресоциализации заключенных. Таким образом, осуществлялось повышение профессиональной компетентности педагогов исправительных учреждений по вопросам реализации образовательных программ, осуществляемых в них.

2. Повышение квалификации в системе непрерывного профессионального образования. В рамках указанного направления было организовано посещение педагогами семинаров, мастер-классов и семинаров-практикумов по различным вопросам социально-педагогической подготовки осужденных к освобождению в исправительной колонии. На данных занятиях обсуждались возможности использования метода проектов и инновационных технологий в работе с заключенными, проблемы работы в разновозрастных группах, когда приходится действовать среди осужденных разного возраста, имеющих разный жизненный опыт и разные индивидуально-психологические характеристики. Кроме того, организовывалось участие педагогов в различных вебинарах, посвященных проблемам социально-педагогической работы с осужденными, в том числе, направленной на их ресоциализацию и подготовку к освобождению. Все это в своей совокупности позволяло развить профессиональные компетенции педагогов, сформировать у них способность к организации различных форм практической работы с осужденными, а также повысить их профессиональную компетентность в области использования информационно-коммуникационных технологий в своей профессиональной деятельности.

3. Обобщение и распространение собственного педагогического опыта. В рамках данного направления осуществлялось создание педагогами проектов, посвященных их собственному профессиональному опыту в области социально-педагогической подготовки осужденных к освобождению в исправительных учреждениях. Проект включал теоретическую часть и 
презентацию, в которых описывалось содержание опыта работы. На занятиях представленные проекты обсуждались, выделялись основные моменты, связывающие каждый из проектов и составляющие основу профессиональной деятельности педагогов в сфере работы с осужденными, отмечались возможны профессиональные ошибки и способы их исправления. В результате выбирались наиболее удачные проекты, которые впоследствии могли быть представлены на различных мероприятиях, посвященных социально-педагогической работе с осужденными, на муниципальном и региональном уровнях.

Таким образом, повышение квалификации педагогов охватывало не только область их работы по социально-педагогической подготовке осужденных к освобождению, но и их общие педагогические навыки. Развивалась способность и стремление педагогов использовать в своей работе информационно-коммуникационные технологии, строить работу с учетом индивидуально-личностных особенностей заключенных. Кроме того, педагогам прививалось понимание необходимости проведения указанного рода подготовки, у них развивались навыки педагогической и психологической оценки осужденных, формировались гуманистические и альтруистические качества, развивалось критическое мышление.

В целом, представленная система работы включала в себя все необходимые направления. Была организована социально-педагогическая подготовка осужденных в период, предшествующий освобождению, а также подготовка персонала к организации социально-педагогической подготовки осужденных в период, предшествующий освобождению. Кроме того, были выполнены необходимые организационные условия: создана необходимая социально-педагогическая среда, организовано взаимодействие осужденных с представителями общественных и религиозных организаций.

В ходе работы было отмечено повышение интереса педагогов исправительных учреждений к проводимой работе, развитие в них более лояльного и гуманного отношения к осужденными, формирование стремления получать новую информацию в сфере их социально-педагогической подготовки к освобождению. Заключенные, в свою очередь, стали активнее включаться в занятия, проявляли интерес к рассматриваемым сторонам жизни, увереннее проявляли себя в бытовых ситуациях, показывали стремление к получению информации о жизни вне исправительного учреждения. Развились социальные навыки осужденных: проявилась способность адекватно воспринимать чужую точку зрения и контролировать свои собственные эмоции, критически относиться к получаемым сведениям и выделять в них главное, что особенно важно, учитывая контингент, который, как правило, является основным источником информации в местах заключения.

$$
* * *
$$

1. Колесникова, Н.Е. Организация психологического сопровождения осужденных к наказаниям без изоляции от общества / Н.Е. Колесникова // Ученые записки Санкт-Петербургского им. В.Б. Бобкова филиала Российской таможенной академии. - 2015. - № 2 (54). - С. 125-132.

2. Санитарно-эпидемиологические правила и нормативы СанПиН 2.4.2.2821-10 «Санитарноэпидемиологические требования к условиям организации обучения в общеобразовательных организациях» // Гарант. Информационно-правовое обеспечение. https://base.garant.ru/12183577/53f89421bbdaf741eb2d1ecc4ddb4c33/ (дата обращения 23.06.2020).

3. Приказ Минздрава РФ от 16.09.2003 № 438 «О психотерапевтической помощи» // КонсультантПлюс надежная правовая поддержка. - http://www.consultant.ru/document/cons_doc_LAW_94742/ (дата обращения 25.06.2020).

4. Вилкова А.В. Проблема формирования духовно-нравственных ценностей несовершеннолетних осужденных женского пола / Вилкова А.В. // Историческая и социально-образовательная мысль. 2016. № 4. С. 115.

5. Митькина А.В. Некоторые вопросы организации борьбы с незаконным оборотом наркотиков / А.В. Митькина // Уголовно-исполнительная система: право, экономика, управление. 2013. № 3. С.3. 